\title{
Mathematical Modeling of Dual Intake Transparent Transpired Solar Collector
}

\author{
Thomas Semenou, ${ }^{1}$ Daniel R. Rousse, ${ }^{1}$ Brice Le Lostec, ${ }^{2}$ \\ Hervé F. Nouanegue, ${ }^{2}$ and Pierre-Luc Paradis ${ }^{1}$ \\ ${ }^{1}$ Technologies of Energy and Energy Efficiency Industrial Research Chair (t3e), Department of Mechanical Engineering, \\ École de Technologie Supérieure, Université du Québec, 1100 Notre-Dame Street West, Montreal, QC, Canada H3C 1K3 \\ ${ }^{2}$ Laboratory of Technologies of Energy (LTE), 600 Mountain Avenue, Shawinigan, QC, Canada G9N 7N5
}

Correspondence should be addressed to Daniel R. Rousse; daniel@t3e.info

Received 22 April 2015; Revised 16 June 2015; Accepted 23 June 2015

Academic Editor: Manfred Krafczyk

Copyright (C) 2015 Thomas Semenou et al. This is an open access article distributed under the Creative Commons Attribution License, which permits unrestricted use, distribution, and reproduction in any medium, provided the original work is properly cited.

Nowadays, in several types of commercial or institutional buildings, a significant rise of transpired solar collectors used to preheat the fresh air of the building can be observed. Nevertheless, when the air mass flow rate is low, the collector efficiency collapses and a large amount of energy remains unused. This paper presents a simple yet effective mathematical model of a transparent transpired solar collector (TTC) with dual intake in order to remove stagnation problems in the plenum and ensure a better thermal efficiency and more heat recovery. A thermal model and a pressure loss model were developed. Then, the combined model was validated with experimental data from the Solar Rating and Certification Corporation (SRCC). The results show that the collector efficiency can be up to $70 \%$ and even $80 \%$ regardless of operating conditions. The temperature gain is able to reach $20^{\circ} \mathrm{K}$ when the solar irradiation is high.

\section{Introduction}

Nearly $98 \%$ of the Quebec electric energy is produced with hydropower, a clean and renewable energy source. Therefore, it seems to be important to make the best use of it. In this perspective, Quebec should encourage the use of heat pumps which have higher performance than electric baseboards. Nevertheless, heat pumps performance falls drastically when the outside temperature decreases. Also according to HydroQuebec statistics [1], 77\% of households are heated with electricity and $90 \%$ of them also use electricity to produce domestic hot water. These two consumption functions represent about $45 \%$ of the global winter Quebec residential consumption of electricity. Moreover, this heating load is responsible for massive and costly purchase of electricity in winter when the power demand of the network exceeds its capacity. Therefore, it may be conceivable to connect the heat pump evaporator with thermal solar collectors directly or indirectly to maintain the COP above 1 , even when the outside temperature is very low.
The objective of this paper is to present a simple model for thermal solar collectors to be used in the design steps of an installation without the use of Computational Fluid Dynamics (CFD) simulations at each step of the design. The interest in such a simple prediction method is that it allows the analyst to use a simple and very fast tool to test several design possibilities without the costs of expensive standard CFD simulations with in-house or commercial tools.

The selected solar technology in this paper is based on transpired collectors. These collectors, unglazed or transparent, are usually used to preheat fresh air for large commercial and institutional buildings. In this paper, a transparent transpired collector is modeled with an intake at each end: the first one is dedicated to preheat fresh air for the building while the second one would be linked to the heat pump evaporator. The genuine mathematical model combines a thermal model with a pressure loss model in order to determine the incidence of the second intake on the performances of the collector. A parametrical study was performed to measure the impact of 
the operating mass flow rate, the solar irradiation, and the outside temperature on the thermal performances of the solar wall.

\section{A Selected Literature Review}

2.1. Unglazed and Transparent Transpired Collectors. Unglazed transpired collectors (UTC) have been investigated intensively since about 1980. Kutscher [2] was among the first to study this technology. For this purpose, he compared analytical results obtained with a thermal balance on the collector with experimental results. In this way, he has been able to identify the most influencing parameters on the solar collector performances. Thus, the wind effect is limited for suction speeds higher than $0.05 \mathrm{~m} / \mathrm{s}$ and it is recommended to use a selective absorber coating on the perforated plate. Moreover, based on an analysis of thermal losses, he asserted that natural convection operating at the outside of the collector was negligible. This statement was also confirmed later by Arulanandam et al. [3]. Then, he conducted a numerical CFD simulation (Computational Fluid Dynamics), simplified thanks to symmetry elements, on a perforation and its adjacent location. He was thus able to establish a correlation on the perforated plate's thermal efficiency depending on dimensionless parameters such as porosity, the Reynolds number, and the plate's absorptivity. The plate's thermal efficiency is mainly influenced by the first two parameters.

For their part, Leon and Kumar [4] have developed a mathematical modeling based on a thermal model and empirical relationships in order to predict the thermal performances of the solar collector depending on operating conditions. The studied parameters were porosity, air mass flow rate, solar radiation, plate's absorptivity, and emissivity. Their studies were more oriented for drying applications. Lixin and Xiumu [5] obtained similar results with the same type of study, which are that air mass flow rate and solar radiation represent the most influencing parameters on the system efficiency which can reach 70 to $80 \%$.

Summers [6] developed a numerical model with TRNSYS software based on a thermal balance allowing us to determine the energy potential and the payback period. He concludes that the technology should be recommended for large residential buildings. Later, Delisle [7] adapted her model to simulate the addition of photovoltaic cells on the transpired solar collector. In recent years, this type of coupling is specifically investigated. Indeed, it allows us to recover heat while increasing the electrical efficiency of photovoltaic cells [8]. The TTC enables us to minimize the cells' temperature and therefore to increase the efficiency. Nevertheless, the additional incurred costs do not justify the low rise of the electrical efficiency.

A modification of the unglazed transpired solar collector appeared in recent years: the transparent transpired solar collector. It looks like the UTC; the only difference is that the perforated plate is semitransparent and the inner wall becomes the absorber. Thus, the air is warming up crossing perforations and also when it is circulating into the plenum. In Canada, such a technology was patented by Enerconcept
[9]. Thermal performances are similar to those of UTC but collectors look more discreet from an esthetical point of view.

2.2. Solar Collectors and Heat Pumps. Many researches have been conducted on different coupling techniques between heat pumps and solar collectors. Thus, systems can be categorized as follows: parallel coupling, serial coupling, or mixed coupling. In parallel coupling, the heat pump receives heat from ambient environment and the energy produced by the solar collector is directly provided to the relevant application [10]. In serial coupling, the solar energy is solely provided to the heat pump evaporator, whereas in a mixed coupling the evaporator is designed to receive heat from solar collectors as well as from ambient environment depending on surrounding conditions [11].

Different types of collectors are usually used:

(i) unglazed or flat plate collectors;

(ii) vacuum tube collectors;

(iii) transpired solar collectors.

A majority of studies in scientific literature deal only with mixed coupling. Indeed, they are more relevant because they allow us to select the hot source origin depending on weather and operating conditions with an appropriate controller.

Çağlar and Yamalı [12] conducted a study on a heat pump connected with a vacuum tube collector to provide hot water with a higher temperature than local outside winter air temperature in Ankara, Turkey. This coupling also enables us to increase the collector efficiency because the outer wall temperature is equal to ambient temperature, thus removing thermal losses.

Other researchers have worked on serial systems in which heat pump evaporator consists in a solar collector. The refrigerant circulates directly in the solar collector $[13,14]$. There are also indirect systems in which the heat pump and the solar collector are linked with a heat exchanger. The fluid circulating in the collector can be air, water, or refrigerant $[15,16]$. All of these studies have been conducted in tropical or temperate climates. Lastly, there are alternative systems such as a vacuum tubes collector coupled with a heat pump using carbon dioxide as a refrigerant fluid [17]. The advantage of this fluid is that, at high temperature and pressure, the refrigerant enters in the supercritical area. Furthermore, its environmental impact is quite lower than that of refrigerant $\mathrm{R}-134 \mathrm{a}$, for instance. Studies have also been conducted on hybrid geothermal systems using solar collectors in addition to the energy delivered by the geothermal field. A study from Rad et al. [16] in Canada's northern climate showed this solution was viable and profitable to domestic hot water heating and space heating.

\section{Materials and Methods}

3.1. Collector Geometry. The investigated solar collector is composed of a semitransparent perforated plate which allows the major fraction of the incident solar radiation (irradiation) to be transmitted to the internal (absorber) wall. The usual 
material for these so-called transparent transpired collectors (TTC) is polycarbonate. Basically, one needs (outside) a material with high transmissivity and low absorptivity to solar radiation. This limits the temperature rise of the cover plate and therefore limits heat losses by radiation and convection to the environment. Combined with an absorber wall with high absorptivity, radiation is then trapped between the cover plate and the wall as the cover plate has a low transmissivity in the near infrared. That is, the radiation emitted by the inner wall is absorbed and reflected back by the cover plate.

A fan located at each end of the wall enables air to be drawn through plate perforations by creating a pressure drop in the plenum. The air is heated by convection when it crosses the perforated plate. Then, the air continues to warm up in contact with the absorber inner wall until the intake ducts. Figure 1 presents a schematic of the collector geometry.

The porosity is used to calculate the convective exchange which takes place when the air flows through the perforated plate. The porosity is calculated by the use of [17]

$$
\sigma=\frac{\pi}{4}\left(\frac{D}{P}\right)^{2} .
$$

3.2. Thermal Modeling. A thermal balance is carried out on the different elements which compose the solar wall, namely, the perforated plate, the absorber wall, and the plenum. For that purpose, the solar collector is discretized into $n$ control volumes in vertical direction so as to set the energy balance equations. The mechanisms of heat transfer are supposed to be one-dimensional, in steady state, and for an adiabatic wall behind the collector. Similar assumptions have already been used in scientific literature [2, 4]. Figure 2 shows the solar wall discretization and the heat transfer mechanism occurring at the node $j$.

The heat exchange, assumed to be in steady state, leads to three conservation energy equations, one for each of the abovementioned elements of the solar wall. The energy balance on the perforated plate at node $j$ yields

$$
\begin{aligned}
& \dot{q}_{\text {conv }, p-a}^{\mid j}+\dot{q}_{\text {rad }, p-\text { sur }}^{\mid j}+\dot{q}_{\text {rad }, p-m}^{\mid j} \\
& \quad+\dot{q}_{\text {conv }, p-\text { wind }}^{\mid j}=\dot{q}_{\text {rad,sol- } p}^{\mid j} \\
& A_{j} h_{\text {conv }, p-a}^{\mid j}\left(T_{p}^{\mid j}-T_{a}^{\mid j}\right)+A_{j} h_{\text {rad, } p-\text { sur }}^{\mid j}\left(T_{p}^{\mid j}-T_{\text {sur }}\right) \\
& \quad+A_{j} h_{\text {rad }, p-m}^{\mid j}\left(T_{p}^{\mid j}-T_{m}^{\mid j}\right) \\
& \quad+A_{j} h_{\text {conv }, p-\text { wind }}^{\mid j}\left(T_{p}^{\mid j}-T_{\text {amb }}\right)=\alpha_{\text {eff }, p}^{\mid j} A_{j} G_{\text {sol }} .
\end{aligned}
$$

The energy balance on the absorber wall at node $j$ is given by

$$
\begin{aligned}
& \dot{q}_{\text {conv }, m-a}^{j}-\dot{q}_{\mathrm{rad}, p-m}^{\mid j}=\dot{q}_{\mathrm{rad}, \mathrm{sol}-m}^{\mid j}, \\
& A_{j} h_{\text {conv }, m-a}^{\mid j}\left(T_{m}^{\mid j}-T_{a}^{\mid j}\right)-A_{j} h_{\mathrm{rad}, p-m}^{\mid j}\left(T_{m}^{\mid j}-T_{p}^{\mid j}\right) \\
& \quad=\alpha_{\mathrm{eff}, m} A_{j} G_{\mathrm{sol}} .
\end{aligned}
$$

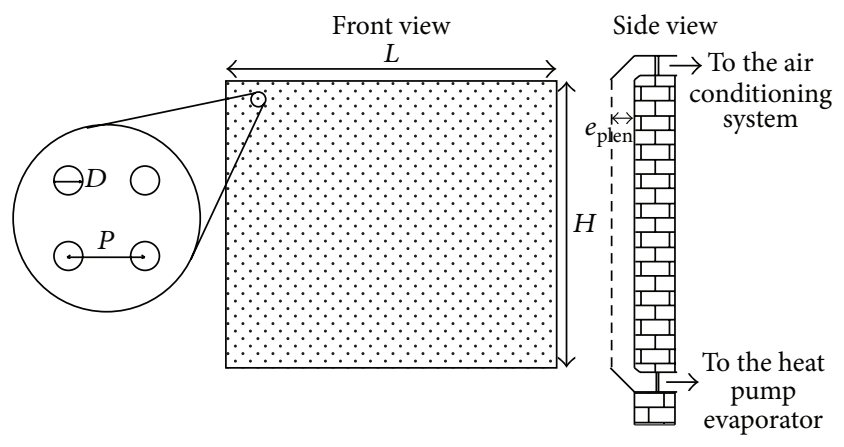

FIGURE 1: Transparent transpired solar wall with dual intake.

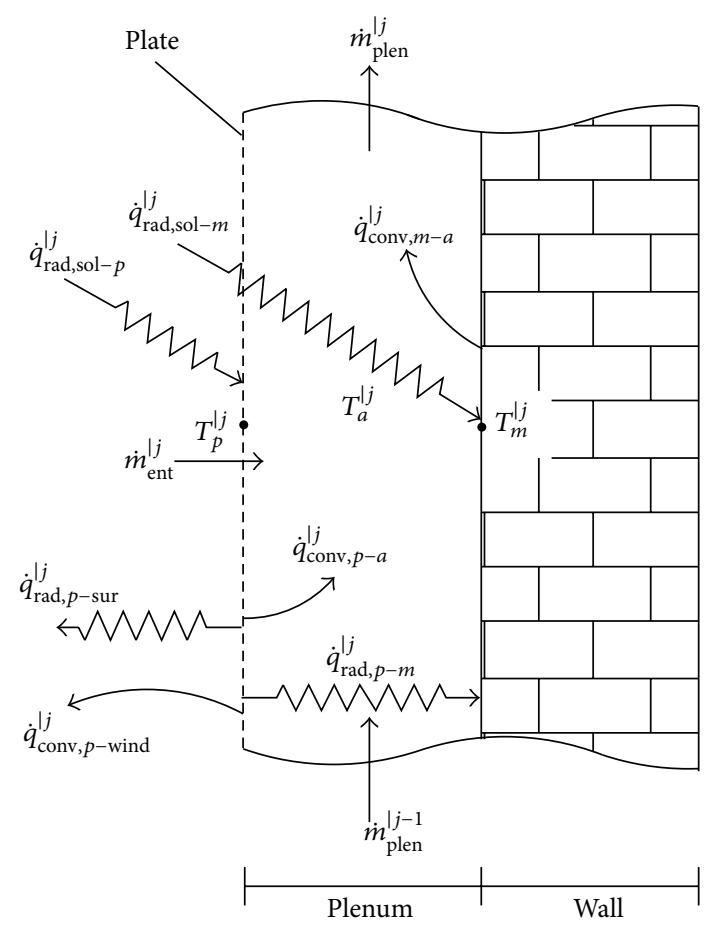

FIgURE 2: Thermal model of solar collector at node $j$.

And the energy balance on the air flowing in the plenum at node $j$ can be expressed such that

$$
\begin{aligned}
- & \dot{q}_{\text {conv }, m-a}^{\mid j}-\dot{q}_{\text {conv }, p-a}^{\mid j}+m_{\text {ent }}^{\mid j} c_{p, \text { ent }}^{\mid j} \varepsilon_{\text {conv }, p}^{\mid j} T_{\text {ent }}^{\mid j} \\
& +m_{\text {plen }}^{\mid j-1} c_{p, a}^{\mid j-1} T_{a}^{\mid j-1}=m_{\text {plen }}^{\mid j} c_{p, a}^{\mid j} T_{a}^{\mid j}, \\
- & A_{j} h_{\text {conv }, m-a}^{\mid j}\left(T_{a}^{\mid j}-T_{m}^{\mid j}\right)-A_{j} h_{\text {conv }, p-a}^{\mid j}\left(T_{a}^{\mid j}-T_{p}^{\mid j}\right) \\
& +m_{\text {ent }}^{\mid j} c_{p, \text { ent }}^{\mid j} \varepsilon_{\text {conv }, p}^{\mid j} T_{\text {ent }}^{\mid j} \\
& +m_{\text {plen }}^{\mid j-1} c_{p, a}^{\mid j-1} T_{a}^{\mid j-1}=m_{\text {plen }}^{\mid j} c_{p, a}^{\mid j} T_{a}^{\mid j} .
\end{aligned}
$$

In the conservation equations, the convective exchange coefficient between the perforated plate and the air flowing 
into the plenum is calculated with Kutscher's correlation [2]:

$$
h_{\text {conv }, p-a}^{\mid j}=\frac{\mathrm{Nu}_{D}^{\mid j} k_{a}^{\mid j}}{D} .
$$

The Nusselt number, $\mathrm{Nu}_{D}$, also comes from the experimental work of Kutscher [2]. The collector is assumed to be a small object surrounded by an environment with constant outside temperature. Therefore, the radiative exchange coefficient between the plate and the surroundings is given by the following equation derived from Bergman et al. [18]:

$$
\begin{aligned}
& h_{\text {rad,p-sur }}^{\mid j} \\
& \quad=\varepsilon_{p} \sigma_{\mathrm{SB}} A_{j}(1-\sigma)\left(T_{p}^{\mid j}+T_{\text {sur }}\right)\left(T_{p}^{\mid j^{2}}+T_{\text {sur }}^{2}\right) .
\end{aligned}
$$

The convective exchange coefficient between the plate and the external environment which represents the losses to wind is determined according to Delisle's work [7] on transpired solar collectors:

$$
h_{\text {conv }, p-\text { wind }}^{\mid j}=A_{j}(1-\sigma)\left(6+4 \times u_{\text {wind }}-76 \times u_{\text {ent }}^{\mid j}\right) \text {. }
$$

The radiative exchange coefficient between the perforated plate and the absorber wall is obtained from the approximation of the radiative exchange between two parallel plates presented by Bergman et al. [18]:

$$
\begin{aligned}
& h_{\mathrm{rad}, p-m}^{\mid j} \\
& =\frac{\sigma_{\mathrm{SB}}\left(T_{p}^{\mid j}+T_{m}^{\mid j}\right)\left(T_{p}^{\mid j^{2}}+T_{m}^{\mid j^{2}}\right)}{\left(1-\varepsilon_{p}\right) / \varepsilon_{p} A_{j}(1-\sigma)+1 / A_{j}(1-\sigma)+\left(1-\varepsilon_{m}\right) / \varepsilon_{m} A_{j}} .
\end{aligned}
$$

Finally, the convective exchange coefficient between the wall and the air flowing in the plenum is calculated according to Leon and Kumar's work [4]:

$$
h_{\mathrm{conv}, m-a}^{\mid j}=\frac{\mathrm{Nu}_{m}^{\mid j} k_{a}^{\mid j}}{e} .
$$

The Nusselt number along the wall depends on the flow regime (laminar or turbulent).

3.3. Pressure Loss Modeling. In several papers taken from the scientific literature, the air inflow into the solar collector is assumed constant for the entire height of the wall [2-4]. However, this is an approximation that may be challenged. Indeed, it can be expected that the closest the location is from the exhaust fan (the building intake), the more important the air mass flow rate will be. For this purpose, a suitable pressure loss model enables us to identify, for any operating conditions, which fraction of the solar wall is really used by the fresh air intake. Thus, the unused fraction of the collector, that is, the portion of the collector away from the (upper) fresh air intake, will now be linked with the second (lower) air intake to preheat the evaporator. The pressure drop model is based on and adapted from Kutscher [2] and Motahar and
Alemrajabi [19] studies. In their papers, the authors assumed that the fan balances the whole pressure loss due to the solar collector. Thus, for a value of power and of air flow rate, the pressure loss is given by the following equation:

$$
\Delta P=\frac{W \rho}{\dot{m}_{\text {out }}} .
$$

All pressure losses can be decomposed as follows:

$$
\Delta P=\Delta P_{c}+\Delta P_{b}+\Delta P_{f}+\Delta P_{a} .
$$

Pressure losses through the perforations are calculated with the formula taken from Kutscher's work [2]:

$$
\Delta P_{c}^{\mid j}=\frac{1}{2} \rho_{a}^{\mid j}\left(6.82\left(\frac{1-\sigma}{\sigma}\right)^{2} \operatorname{Re}_{D}^{\mid j^{-0.236}}\right) u_{\mathrm{ent}}^{\mid j} .
$$

Pressure losses due to buoyancy strengths are given by

$$
\Delta P_{b}^{\mid j}=\frac{1}{2}\left(\rho_{\text {plen }}^{\mid j}-\rho_{\text {plen }}^{\mid j+1}\right) g \frac{H}{n} .
$$

Pressure losses due to frictional strengths are calculated with the following equation:

$$
\Delta P_{f}^{\mid j}=f \frac{(H / n) \rho_{\text {plen }}^{\mid j}\left(u_{\text {plen }}^{\mid j}\right)^{2}}{2 D_{H}} .
$$

Finally, pressure losses due to acceleration are given by

$$
\Delta P_{a}^{\mid j}=\frac{1}{2}\left[\rho_{\text {plen }}^{\mid j}\left(u_{\text {plen }}^{\mid j}\right)^{2}-\rho_{\text {plen }}^{\mid j+1}\left(u_{\text {plen }}^{\mid j+1}\right)^{2}\right] .
$$

On the top part of the wall, the solving is done from top to bottom according to Figure 3 because the pressure and the air flow rate are known at the outlet of the solar wall.

Thus, operating conditions are known at point 1 . The next step consists in calculating pressure losses between points 1 and 2, respectively, $\Delta P_{b}, \Delta P_{f}$, and $\Delta P_{a}$. The pressure value at point 2 is calculated by adding pressure losses to the pressure value at point 1 . Then, the pressure losses through the perforated plate, point 3 , are equal to the difference between the atmospheric pressure and the pressure value at point 2 . The air velocity flowing into the plenum is obtained by (12). Lastly, we assume that the pressure value at point 4 is the same as at point 3 and, therefore, the air flow rate at node $j+1$ can be determined such that

$$
\dot{m}_{\text {plen }}^{\mid j+1}=\dot{m}_{\text {plen }}^{\mid j}-\dot{m}_{\text {ent }}^{\mid j} .
$$

The process is repeated until the air flow rate in the plenum reduces to zero. The solving method is the same for the bottom part of the wall; steps are just followed in the other direction according to Figure 4 . The pressure value at point 1 is assumed to be the same as at the last point of the high part pressure loss model and the air flow rate is considered equal to the air inflow rate at the node $j-1$. Then, the pressure losses through the perforated plate at point 3 enable us to calculate the air inflow rate at point 3 . The air flow rate at point 2 is thus obtained by adding it to the air flow rate at point 1 . Similarly, 


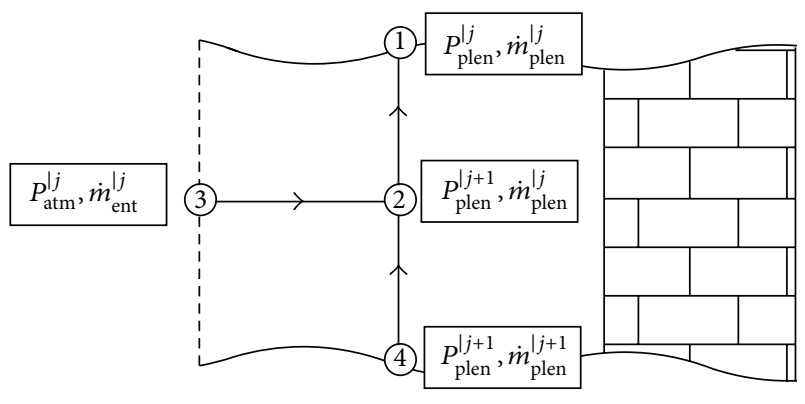

FIgure 3: Pressure loss model on high part of the wall at node $j$.

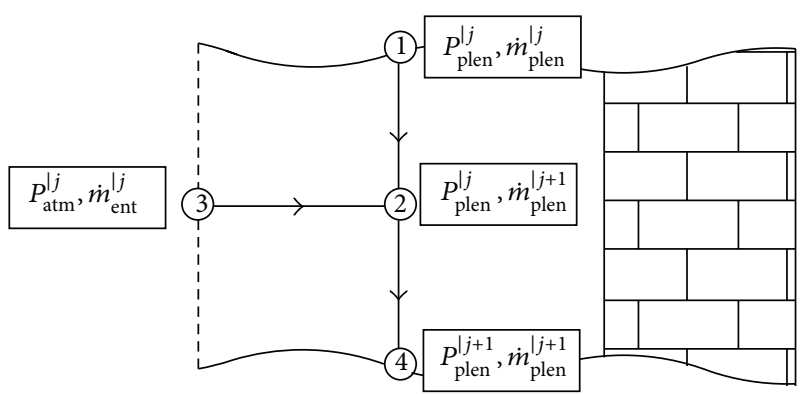

Figure 4: Pressure loss model on the low part of the wall at node $j$.

the next step consists in calculating pressure losses between points 2 and 4 , respectively, $\Delta P_{b}, \Delta P_{f}$, and $\Delta P_{a}$. The pressure value at point 4 is calculated by adding pressure losses to the pressure value at point 2 .

In this way, the air outflow from node $n$ represents the operating flow rate of the fan and the pressure at the exit of this node enables us to determine the pressure loss balanced by the fan.

3.4. Resolution Algorithm. Figure 5 shows the resolution algorithm developed in order to obtain the temperature vectors.

3.5. Numerical Details. In Figure 5, the initial temperature vectors, $T$, for the cover plate, the wall, and the air in the plenum are set to $T_{\mathrm{amb}}$, the ambient temperature. Thus, the properties and radiative heat transfer coefficients are first evaluated at this temperature. Then, the fluid properties are recalculated by use of standard interpolations (embedded in an independent subroutine) between $250 \mathrm{~K}, 300 \mathrm{~K}$, and $350 \mathrm{~K}$ in the tables provided in the textbook by Bergman et al. [18]. As evidenced by (8), since the radiative exchange coefficients explicitly involve surface temperatures, the process is iterative and the values of these radiative coefficients are updated from one iteration to the next.

The simulations were obtained using 50, 100, 200, and 400 nodes. As the solution was insensitive to the number of nodes after 200, this grid was used to provide the results presented in the next section.

The calculations were performed on a 5 th generation Intel Core i7 Pro Laptop. And typical CPU times range from 2 to 10 minutes according to the grid used and the problem solved.
TABLE 1: Collector parameters.

\begin{tabular}{lc}
\hline Collector's height, $H[\mathrm{~m}]$ & 2.448 \\
Collector's width, $L[\mathrm{~m}]$ & 1.836 \\
Collector's depth, $e_{\text {plen }}[\mathrm{m}]$ & 0.150 \\
Perforations diameter, $D[\mathrm{~m}]$ & 0.002 \\
Perforations pitch, $p[\mathrm{~m}]$ & 0.016 \\
Plate absorptivity, $\alpha_{p}$ & 0.14 \\
Plate transmissivity, $\tau_{p}$ & 0.78 \\
Plate reflectivity, $r_{p}$ & 0.08 \\
Plate emissivity, $\varepsilon_{p}$ & 0.86 \\
Wall absorptivity, $\alpha_{m}$ & 0.93 \\
Wall reflectivity, $r_{m}$ & 0.06 \\
Wall emissivity, $\varepsilon_{m}$ & 0.88 \\
Pressure drop of the collector, $\Delta P[\mathrm{~Pa}]$ & 125 \\
\hline
\end{tabular}

This indicates that the goal was reached in terms of simplicity and quickness of the solution procedure.

The iterative procedure provides new temperature vectors $\left(T_{a}, T_{p}\right.$, and $\left.T_{m}\right)$ at each iteration of the process. These temperatures are compared to those obtained at the previous iteration until the convergence criteria are reached, $\varepsilon=1 \times$ $10^{-5}$.

Finally, it is worth mentioning that since the properties do not vary much over the $100 \mathrm{~K}$ range concerned with this problem, no convergence problems were observed when solving this linearized discrete problem for the three unknowns, $T_{a}, T_{p}$, and $T_{m}$.

\section{Results and Discussion}

4.1. Model Validation with Experimental Data. Results obtained with the proposed mathematical modeling are first compared with performances evaluated experimentally by the Solar Rating and Certification Corporation (SRCC) [9] for a relatively small collector of about $4.5 \mathrm{~m}^{2}$ involving a single building intake located on top. The model is then validated with a single intake positioned on the top of the plenum. The validation is carried out indoors with a controlled ambient temperature of $293 \mathrm{~K}$ and a solar incident irradiation of $913 \mathrm{~W} / \mathrm{m}^{2}$. Table 1 presents the fixed physical parameters of a commercial solar collector used to validate the model. The two parameters varying are the unit air volumetric flow rate, from 4 to $10 \mathrm{cfm} / \mathrm{ft}^{2}$, and the wind speed, from 1 to $3 \mathrm{~m} / \mathrm{s}$. For this validation test case, the flow rate of 4 to $10 \mathrm{cfm} / \mathrm{ft}^{2}$ corresponds to about $0.024 \mathrm{~kg} / \mathrm{s} / \mathrm{m}^{2}$ to $0.06 \mathrm{~kg} / \mathrm{s} / \mathrm{m}^{2}$, respectively. Data measured or calculated are collector thermal efficiency and temperature gain. Figure 6 shows the converged results.

In general, the results testify that the proposed mathematical model represents very well the solar collector behaviour certified experimentally by SRCC. Figure 6(a) indicates that thermal efficiencies are close to what was measured by SRCC: the maximum discrepancy is about $2 \%$.

This was found to be quite interesting for one-dimensional predictions meaning that the tool can indeed be used for design. Figure 6(b) shows that although the model slightly 


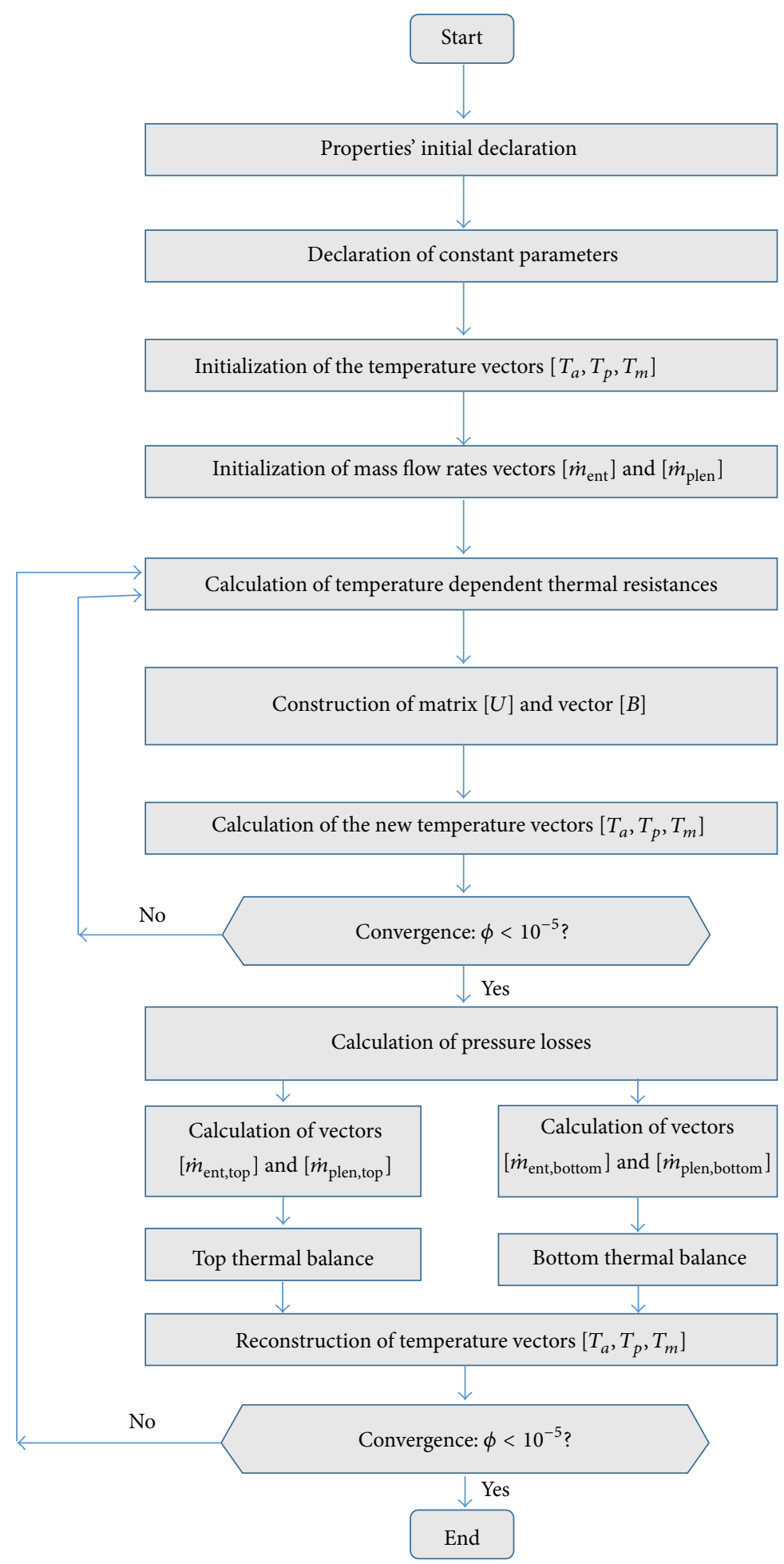

FIgURE 5: Resolution algorithm.

overrates temperature gains measured at the collector air duct, the discrepancy remains below $1.7^{\circ} \mathrm{C}$.

4.2. Effect of the Air Flow Rate. By use of the complete model for dual intake, it is now possible to determine the impact of several environmental parameters on the collector performances for such a configuration. For the proposed study, a typical collector used in a complete yearly campaign of measurements has been selected for the simulations [20]. This collector is about 4 times the size of that of the previous study, 


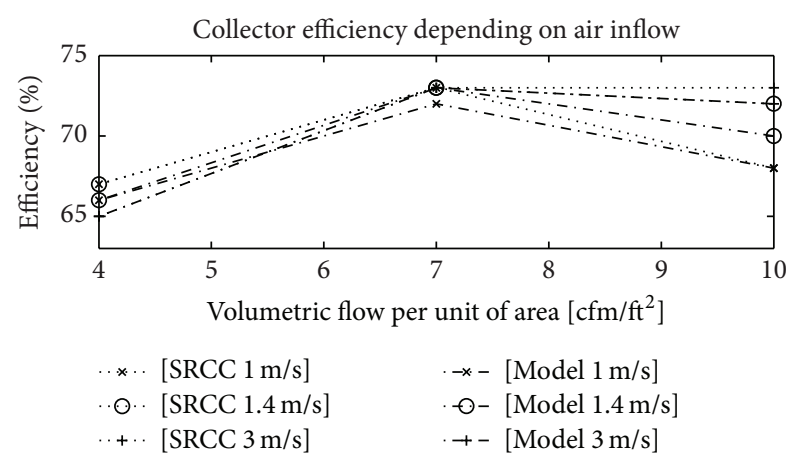

(a)

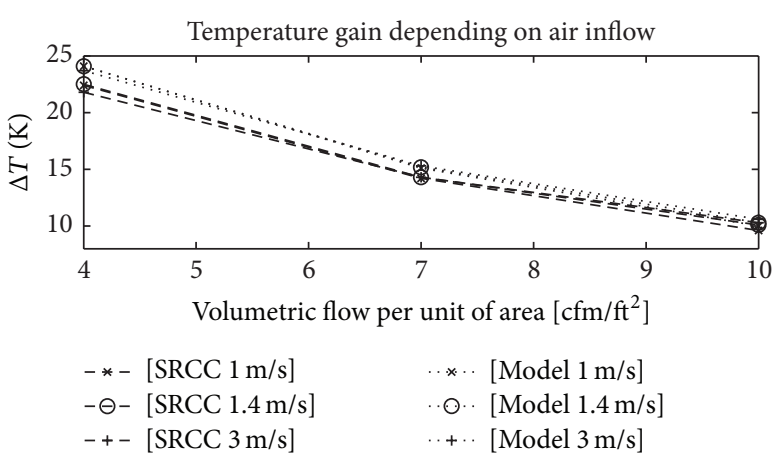

(b)

FIGURE 6: Model validation for three wind speeds: (a) efficiency versus unit air flow rate; (b) temperature gain versus unit air flow rate.

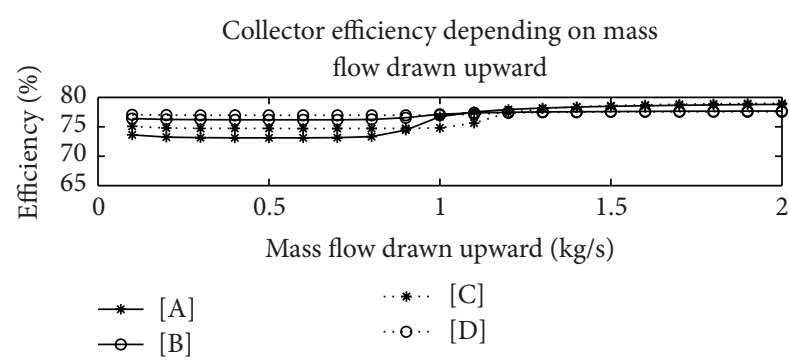

(a)

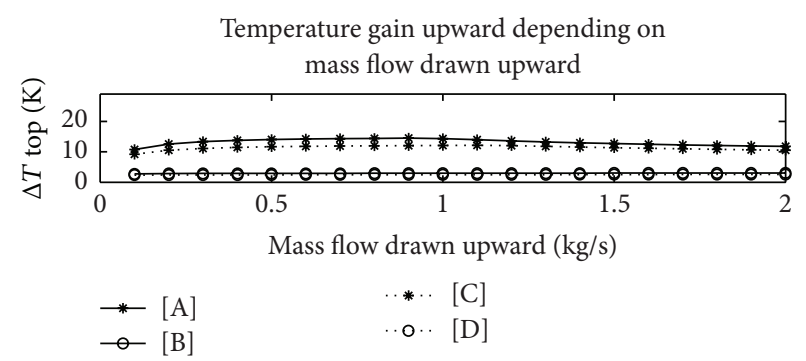

(b)

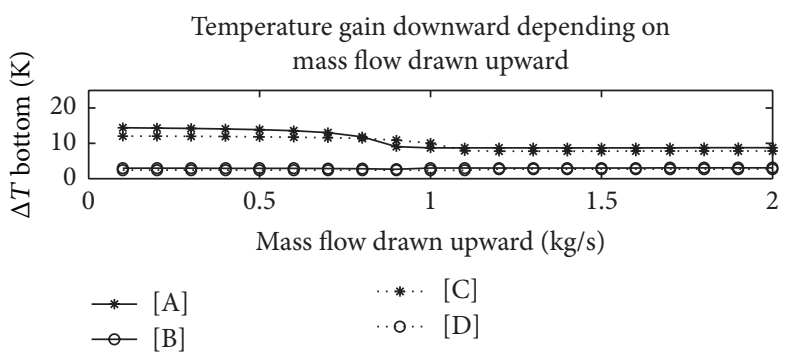

(c)

FiguRE 7: Effect of the mass flow drawn upward on (a) the efficiency; (b) temperature gain in the top intake; (c) temperature gain in the bottom intake.

$4 \mathrm{~m} \times 4.6 \mathrm{~m}$, and the mass flow rate varies from 0.1 to $2.0 \mathrm{~kg} / \mathrm{s}$. For the sake of comparison with the abovementioned validation study, the thermal efficiency and the temperature are used as performance indicators. Thermal efficiency is defined by

$$
\eta=\frac{Q_{u, \text { high }}+Q_{u, \text { low }}}{A_{t} G_{\text {sol }}},
$$

where the useful energy is calculated with the following equations:

$$
\begin{aligned}
\dot{Q}_{u, \text { high }} & =m_{\text {plen,high }}^{\mid j}\left(c_{p, a}^{\mid j} T_{a}^{\mid j}-c_{p, \text { amb }} T_{\mathrm{amb}}\right), \\
Q_{u, \text { low }} & =m_{\text {plen,low }}^{\mid n-j}\left(c_{p, a}^{\mid n-j} T_{a}^{\mid n-j}-c_{p, \text { amb }} T_{\mathrm{amb}}\right) .
\end{aligned}
$$

Thus, the testing procedure consists in fixing the whole parameters and varying alternatively the air flow rate, the solar irradiation, and the outside temperature. Here, a supplemental convergence requirement is needed to match both the temperature (heat balance) and the mass flow rates (pressure) in both intakes.

Table 2 presents four typical days that were simulated. Here, the external ambient temperatures were fixed at $298 \mathrm{~K}$ and $263 \mathrm{~K}$ in summer and winter, respectively, and the wind speed at $1 \mathrm{~m} / \mathrm{s}$ while the irradiation was $1000 \mathrm{~W} / \mathrm{m}^{2}$ and $200 \mathrm{~W} / \mathrm{m}^{2}$ for sunny and cloudy days, respectively.

Figure 7 presents the effect of the air flow rate drawn by the top intake and aimed at the air conditioning system. Results presented in Figure 7 indicate that, with the addition of the second intake, the collector efficiency stays high even when the air conditioning system requires low fresh air flow rates. Indeed, efficiency varies between 70 and $80 \%$ for the four typical days and this corroborates the previous results of Lixin and Xiumu [5]. The temperature gain is about $15 \mathrm{~K}$ for 


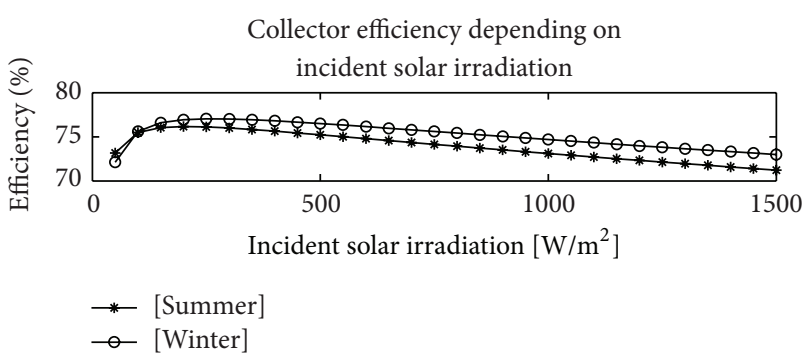

(a)

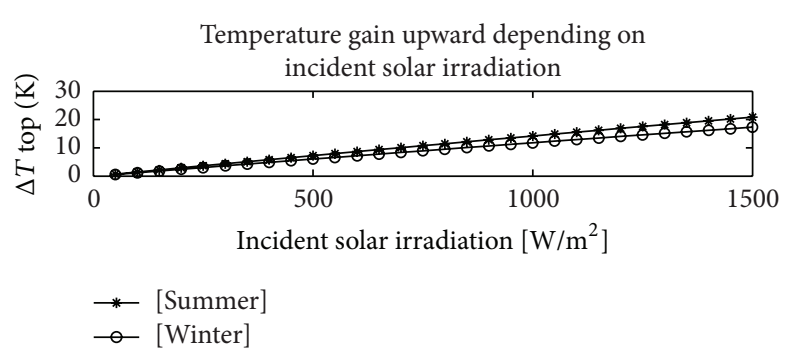

(b)

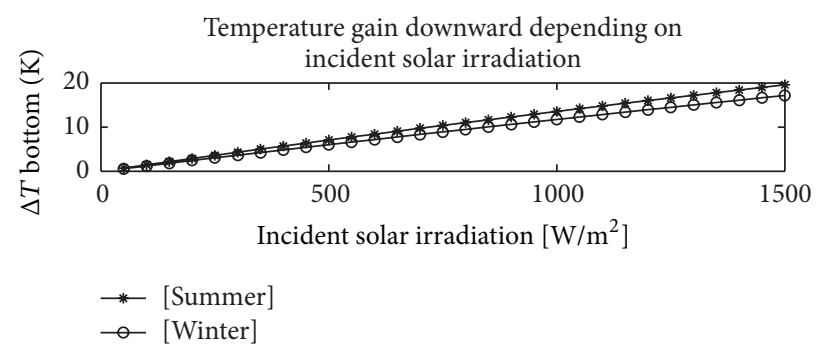

(c)

FIGURE 8: Effect of the variation of solar irradiation on (a) the efficiency; (b) temperature gain in the top intake; (c) temperature gain in the bottom intake.

TABLE 2: Selected input parameters for the simulation.

\begin{tabular}{lcccc}
\hline Case & Type of day & $\begin{array}{c}\text { Outside } \\
\text { temperature }[\mathrm{K}]\end{array}$ & $\begin{array}{c}\text { Solar incident } \\
\text { irradiation } \\
{\left[\mathrm{W} / \mathrm{m}^{2}\right]}\end{array}$ & $\begin{array}{c}\text { Wind } \\
\text { speed } \\
{[\mathrm{m} / \mathrm{s}]}\end{array}$ \\
\hline A & Sunny summer & 298 & 1000 & 1 \\
B & Cloudy summer & 298 & 200 & 1 \\
C & Sunny winter & 263 & 1000 & 1 \\
D & Cloudy winter & 263 & 200 & 1 \\
\hline
\end{tabular}

low air flow rates during sunny days and it tends towards $10 \mathrm{~K}$ when the mass air flow is higher than $1 \mathrm{~kg} / \mathrm{s}$. During cloudy days, the temperature gain is limited to around $3 \mathrm{~K}$ which was expected as there are not many losses to the environment due to the "poor" (low) level of irradiation.

4.3. Effect of the Solar Irradiation. Figure 8 shows the effect of solar irradiation on performances of the TTC for two external temperatures representing summer and winter, respectively, $298 \mathrm{~K}$ and $263 \mathrm{~K}$, and still a constant mass flow rate of $0.6 \mathrm{~kg} / \mathrm{s}$.

In summer or winter, solar collector efficiency is higher when the solar irradiation is low, corresponding to cloudy days. Then, the efficiency decreases linearly but is still higher than $70 \%$. This is due to the fact that the convective and radiative losses to the outside increase when the incident solar irradiation is increasing. With the similar argument, we can justify the fact that the thermal efficiency is slightly higher in winter than in summer. Indeed, winter temperatures are lower than summer temperatures so thermal losses are also lower.

The temperature gain increases linearly with solar irradiation to reach $20 \mathrm{~K}$ in summer contrary to $17 \mathrm{~K}$ in winter when the incident solar irradiation is worth $1500 \mathrm{~W} / \mathrm{m}^{2}$.
4.4. Effect of the External Ambient Temperature. Figure 9 presents the effect of the variation the external ambient temperature for two irradiations, that is, one corresponding to "sunny" conditions $\left(1000 \mathrm{~W} / \mathrm{m}^{2}\right)$ and the other corresponding to "cloudy" conditions $\left(200 \mathrm{~W} / \mathrm{m}^{2}\right)$. The air mass flow rate is still constant $(0.6 \mathrm{~kg} / \mathrm{s})$.

Figure 9 indicates that the variation of outside temperature (reported along the $x$-axis) is shown to be quite limited on all parameters when the sky is cloudy. For instance, on such days, temperature gains are between 2 and $3 \mathrm{~K}$ whatever the outside temperature is. Similarly, collector efficiency decreases slowly when the outside temperature rises indicating a slight corresponding increase in convective and radiative losses. During sunny days, thermal losses being more important due to higher collector temperature for the same mass flow rate than for a cloudy day, the collector efficiency is lower and decreases faster than during cloudy days.

Nevertheless, one should note that although low efficiencies are obtained when either the irradiation or the outside temperature is high, there is a better temperature gain and therefore more energy recovery.

\section{Conclusions}

5.1. Summary. This paper introduces a simple yet accurate mathematical modeling of a transparent transpired solar collector with dual intake that accounts for variable airflow within the perforations of the collecting surface. The model was first validated with selected data from the SRCC for a single intake transparent transpired collector. Then, a second intake was introduced in the model and the application to a real collector was considered. The resulting geometry involves top and bottom building intakes and 


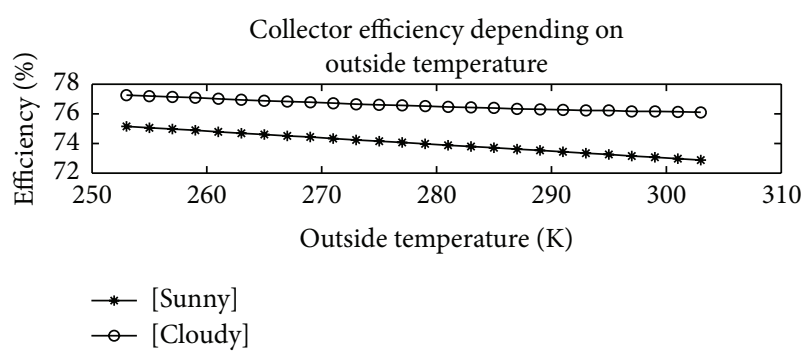

(a)

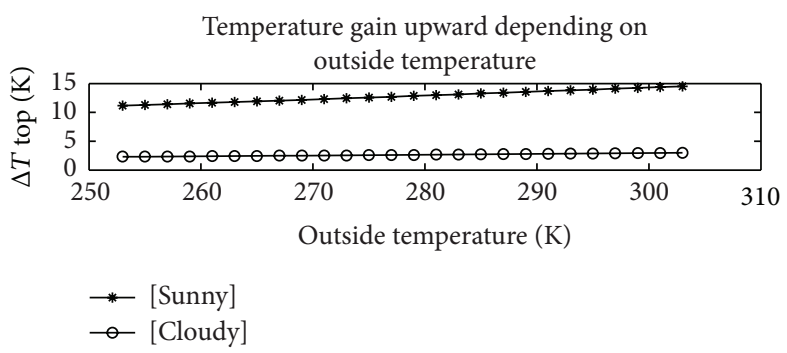

(b)

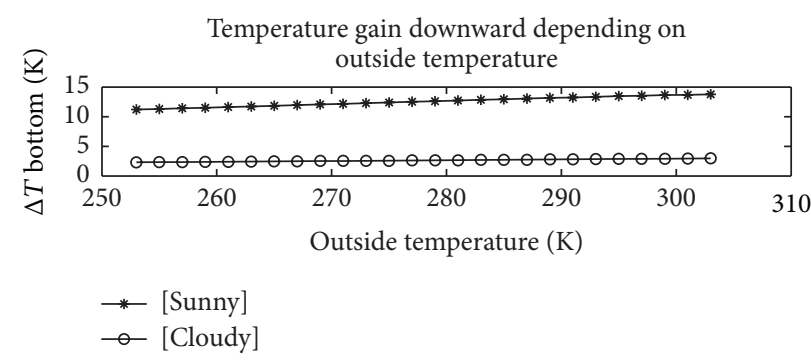

(c)

FIGURE 9: Effect of the variation of the outside temperature on (a) the efficiency; (b) temperature gain in the top intake; (c) temperature gain in the bottom intake.

hence somewhere in between the inflow of air splits to go either upward or downward. The proposed model begins the prediction at the air exits and proceeds backward to compute mass flow rates, temperatures, and pressures within the plenum until a mass, momentum, and energy balance is achieved.

The interest in such a simple prediction methods is that it allows the analyst to use a simple and very fast tool to test several design possibilities without the costs of expensive standard CFD simulations with in-house or commercial tools.

For instance, a parametric study has been carried out to determine the effect of the most influencing parameters including air flow rate, solar irradiation, and external ambient temperature. Results show that the addition of a second intake on the solar collector enables us to maintain high thermal efficiency regardless of operating conditions. The temperature gain is found to be slightly impacted by the external temperature but to increase linearly with the incident solar irradiation.

The relevance of the proposed second intake increases when the collector surface is high, even higher than that considered herein, leading to stagnation zones into which air never reaches the first intake. This second intake therefore collects air that otherwise would not have been collected.

5.2. Recommendation for Future Work. In an upcoming work, it would be mandatory to validate the model against experimental results gathered on a real installation involving two intakes located such as those investigated here. Moreover, as the conditions vary with time, an unsteady version of this code should be developed and heat losses or gain through the wall should be considered.
Once the transient model is validated, the second part of the project could be initiated, that is, a global simulation with TRNSYS involving a first intake devoted to standard preheating of fresh air and the second one linked with the evaporator of a heat pump. This would then determine whether or not the proposed solution is economically viable and under which conditions.

\section{Nomenclature}

$A_{t}: \quad$ Total surface area of the collector $\left(\mathrm{m}^{2}\right)$

$A_{j}$ : Surface area of volume $j\left(\mathrm{~m}^{2}\right)$

$c_{p}: \quad$ Specific heat $(\mathrm{J} / \mathrm{kg} \cdot \mathrm{K})$

$D$ : $\quad$ Diameter of the holes $(\mathrm{m})$

$e_{m}: \quad$ Wall thickness $(\mathrm{m})$

$e_{p}: \quad$ Cover plate thickness $(\mathrm{m})$

$e_{\text {plen }}:$ Depth of the plenum (m)

$f:$ Darcy friction factor

$g: \quad$ Gravitational acceleration $\left(\mathrm{m} / \mathrm{s}^{2}\right)$

$G_{\text {sol }}:$ Incident solar radiation $\left(\mathrm{W} / \mathrm{m}^{2}\right)$

$h: \quad$ Heat transfer coefficient $(\mathrm{W} / \mathrm{K})$

$H: \quad$ Height of the collector $(\mathrm{m})$

$k: \quad$ Thermal conductivity $(\mathrm{W} / \mathrm{m} \cdot \mathrm{K})$

$L: \quad$ Width of the collector $(\mathrm{m})$

$\dot{m}$ : Mass flow rate $(\mathrm{kg} / \mathrm{s})$

$n$ : $\quad$ Number of nodes

$\mathrm{Nu}_{D}$ : Nusselt number through holes

$\mathrm{Nu}_{m}$ : Nusselt number along the wall

p: $\quad$ Pitch (m)

P: $\quad$ Pressure $(\mathrm{Pa})$

Pr: Prandtl number

$\dot{q}: \quad$ Heat flux $(\mathrm{W})$

$r$ : $\quad$ Reflectivity

$\mathrm{Re}_{D}$ : Reynolds number through holes 
$\mathrm{Re}_{m}$ : Reynolds number along the wall

$T: \quad$ Temperature $(\mathrm{K})$

$W$ : Fan power $(\mathrm{W})$.

\section{Greek Symbols}

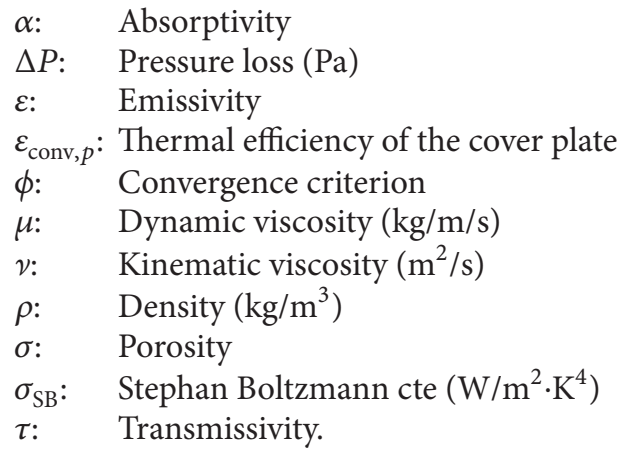

Indices

$a$ : Air circulating in the plenum

amb: Ambient air

atm: Atmospheric

eff: Effective

ent: Fluid entering the plenum

grnd: Ground

$m$ : Absorber wall

$p$ : $\quad$ Cover plate, perforated plated

plen: Fluid circulating in the plenum

sol: Solar

sur: Surroundings.

\section{Exponents}

|j: Nodes identification.

\section{Conflict of Interests}

The authors declare that there is no conflict of interests regarding the publication of this paper.

\section{Acknowledgments}

The first author thanks FRQNT and LTE for the supporting MITACS grant. The authors would like also to thank partners of $\mathrm{t} 3 \mathrm{e}$ industrial research group and Mr. Michel Trottier.

\section{References}

[1] HYDRO-QUÉBEC, Les besoins actuels et futurs du Québec, 2009, http://www.hydroquebec.com/a-propos-hydro-quebec/ projets-construction/pourquoi-projets.html.

[2] C. F. Kutscher, "Heat exchange effectiveness and pressure drop for air flow through perforated plates with and without crosswind," Journal of Heat Transfer, vol. 116, no. 2, pp. 391-399, 1994.

[3] S. J. Arulanandam, K. G. T. Hollands, and E. Brundrett, "A CFD heat transfer analysis of the transpired solar collector under nowind conditions," Solar Energy, vol. 67, no. 1-3, pp. 93-100, 1999.

[4] M. A. Leon and S. Kumar, "Mathematical modeling and thermal performance analysis of unglazed transpired solar collectors," Solar Energy, vol. 81, no. 1, pp. 62-75, 2007.

[5] G. Lixin and F. Xiumu, "Numerical simulation of the thermal performance of solarwall," in Proceedings of the 3rd International Conference on Measuring Technology and Mechatronics Automation (ICMTMA '11), vol. 2, pp. 721-724, IEEE, Shanghai, China, January 2011.

[6] D. N. Summers, Thermal simulation and economic assessment of unglazed transpired collector systems [M.S. thesis], University of Wisconsin-Madison, Madison, Wis, USA, 1995.

[7] V. Delisle, Analytical and experimental study of PV/thermal transpired collector [M.S. thesis], University of Waterloo, 2008.

[8] M. Gholampour, M. Ameri, and M. Sheykh Samani, "Experimental study of performance of PhotovoltaicThermal Unglazed Transpired Solar Collectors (PV/UTCs): energy, exergy, and electrical-to-thermal rational approaches," Solar Energy, vol. 110, pp. 636-647, 2014.

[9] ENERCONCEPT, Produits de chauffage solaire, Lubi, 2012, http://www.enerconcept.com/produits-de-chauffage-solaire/ lubi/.

[10] S. Eicher, C. Hildbrand, A. Kleijer, J. Bony, M. Bunea, and S. Citherlet, "Life cycle impact assessment of a solar assisted heat pump for domestic hot water production and space heating," Energy Procedia, vol. 48, pp. 813-818, 2014.

[11] W. Lerch, A. Heinz, and R. Heimrath, "Evaluation of combined solar thermal heat pump systems using dynamic system simulations," Energy Procedia, vol. 48, pp. 598-607, 2014.

[12] A. Çağlar and C. Yamalı, "Performance analysis of a solarassisted heat pump with an evacuated tubular collector for domestic heating," Energy and Buildings, vol. 54, pp. 22-28, 2012.

[13] J. Facão and M. J. Carvalho, "New test methodologies to analyse direct expansion solar assisted heat pumps for domestic hot water," Solar Energy, vol. 100, pp. 66-75, 2014.

[14] Z. M. Amin and M. N. A. Hawlader, "A review on solar assisted heat pump systems in Singapore," Renewable and Sustainable Energy Reviews, vol. 26, pp. 286-293, 2013.

[15] S. Deng, Y. J. Dai, and R. Z. Wang, "Performance optimization and analysis of solar combi-system with carbon dioxide heat pump," Solar Energy, vol. 98, pp. 212-225, 2013.

[16] F. M. Rad, A. S. Fung, and W. H. Leong, "Feasibility of combined solar thermal and ground source heat pump systems in cold climate, Canada," Energy and Buildings, vol. 61, pp. 224-232, 2013.

[17] G. W. E. Van Decker, K. G. T. Hollands, and A. P. Brunger, "Heatexchange relations for unglazed transpirred solar collectors with circular holes on a square or triangular pitch," Solar Energy, vol. 71, no. 1, pp. 33-46, 2001.

[18] T. L. Bergman, A. S. Lavine, F. P. Incropera, and D. P. Dewitt, Fundamentals of Heat and Mass Transfer, John Wiley \& Sons, 7th edition, 2011.

[19] S. Motahar and A. A. Alemrajabi, "An analysis of unglazed transpired solar collectors based on exergetic performance 
criteria," International Journal of Thermodynamics, vol. 13, no. 4, pp. 153-160, 2010.

[20] L. Guillon, S. Hallé, and D. R. Rousse, "Étude comparative des performances thermiques de collecteurs solaires perforés opaque et transparent," in XIIème Colloque Interuniversitaire Franco-Québécois sur la Thermique des Systèmes, p. 6, Sherbrooke, Canada, 2015. 


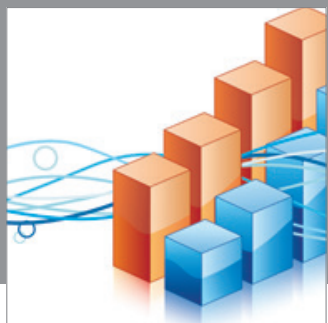

Advances in

Operations Research

mansans

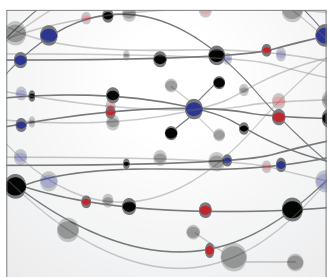

The Scientific World Journal
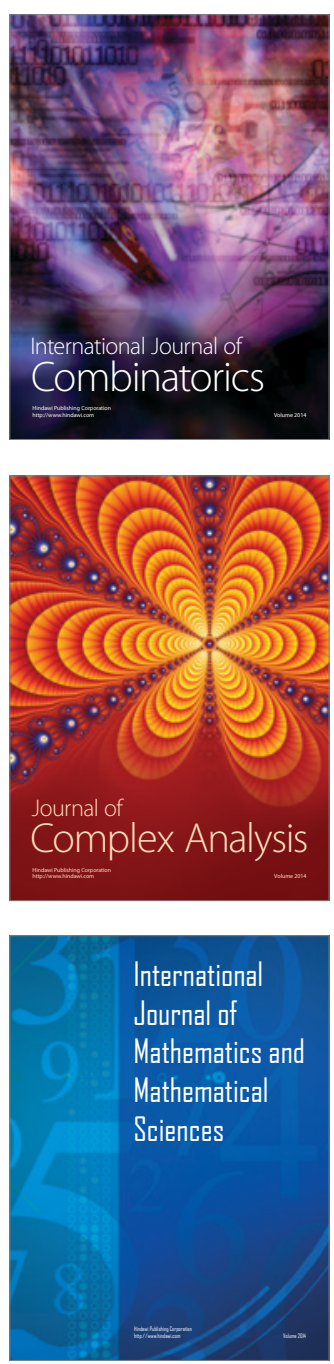
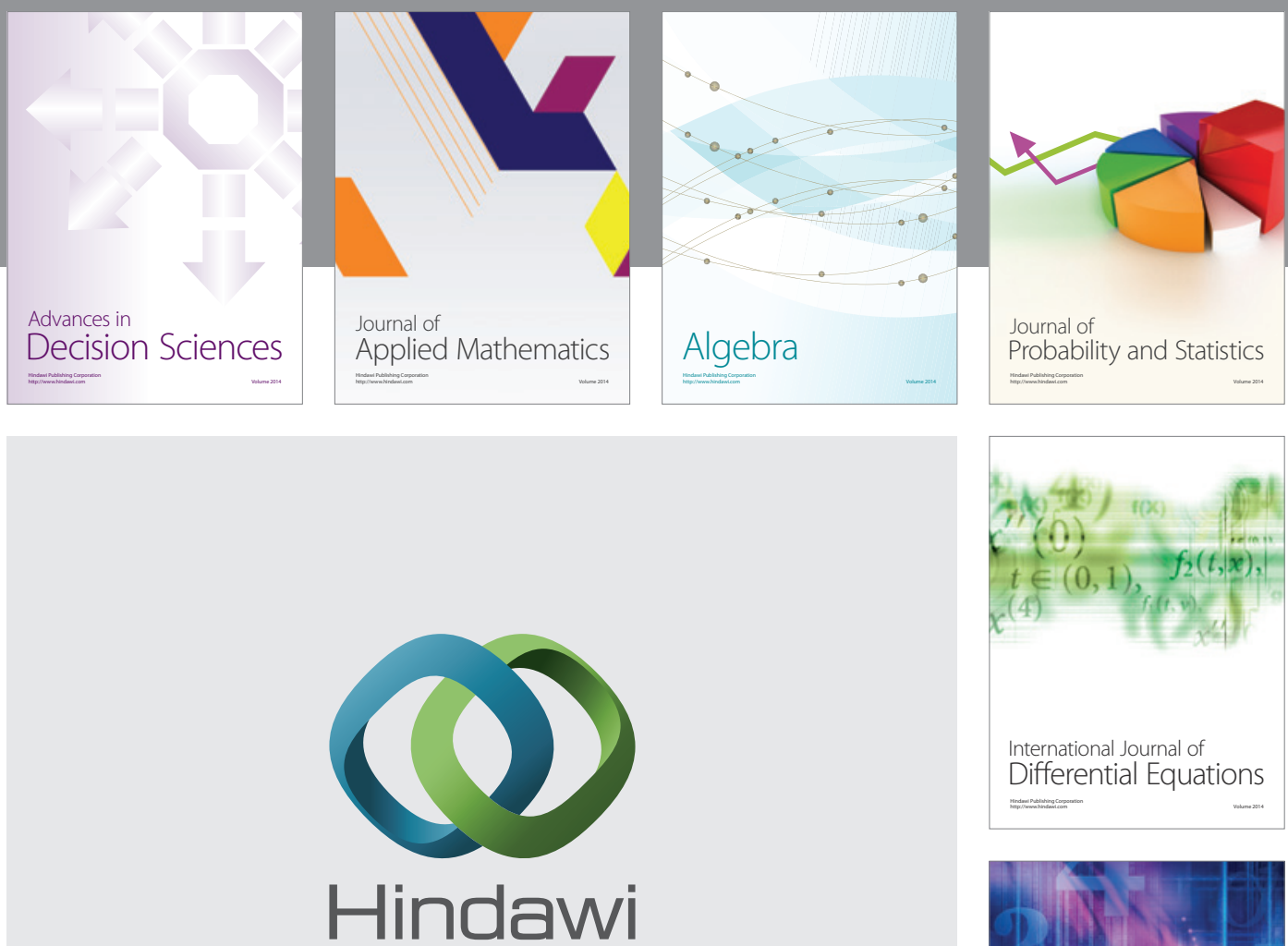

Submit your manuscripts at http://www.hindawi.com
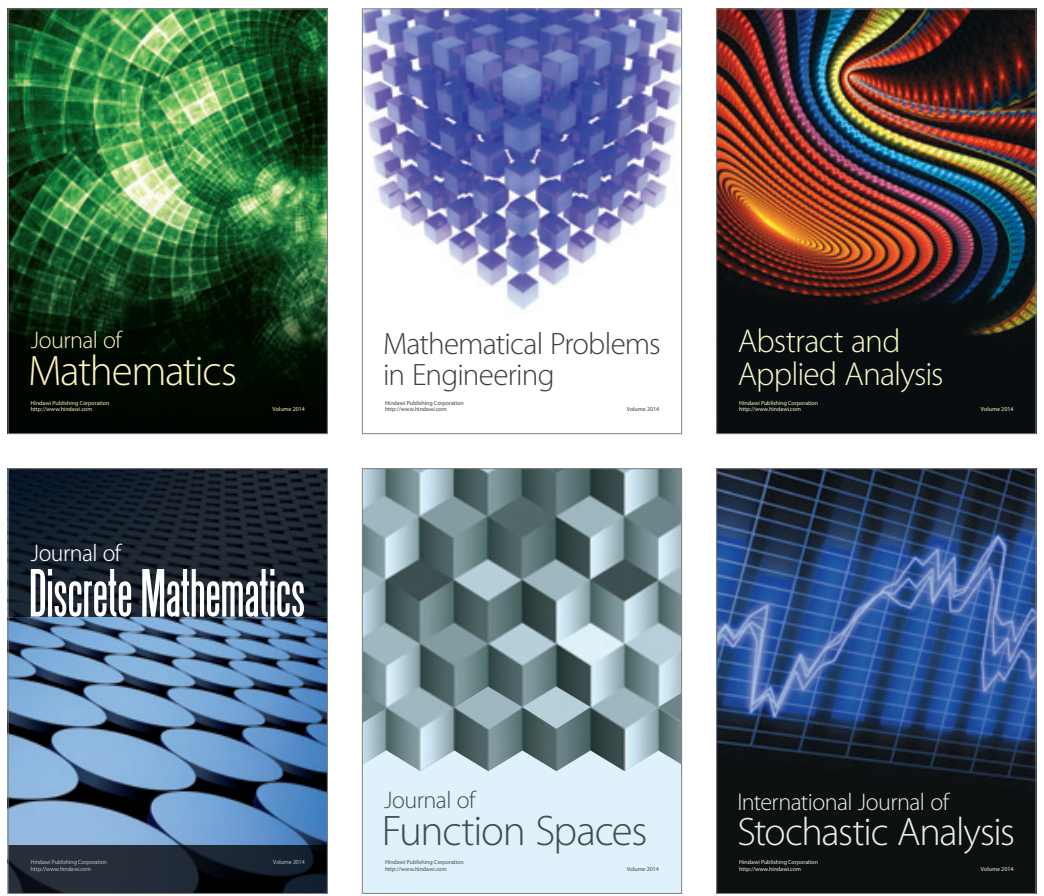

Journal of

Function Spaces

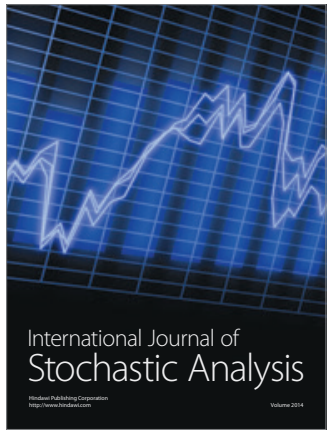

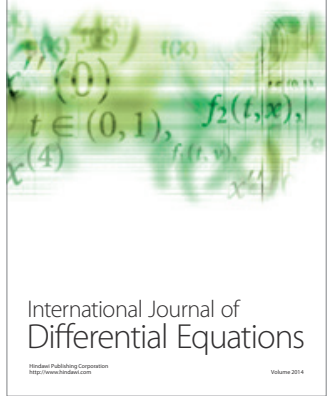
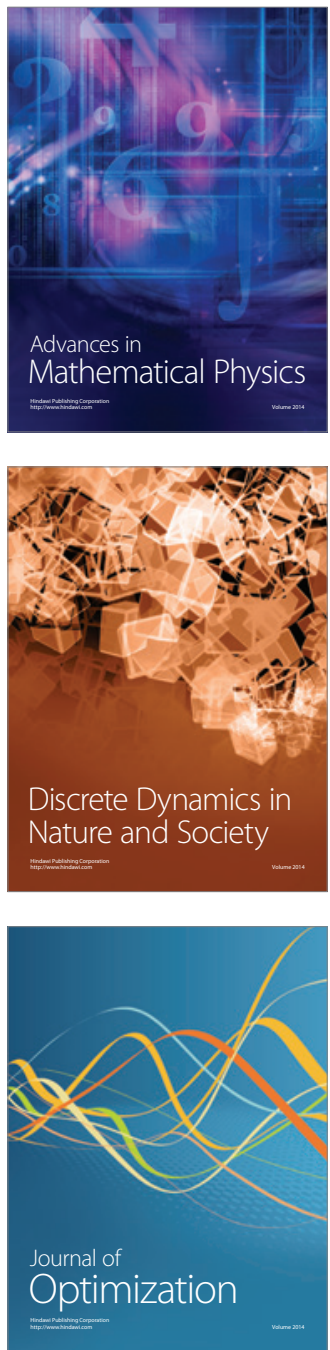